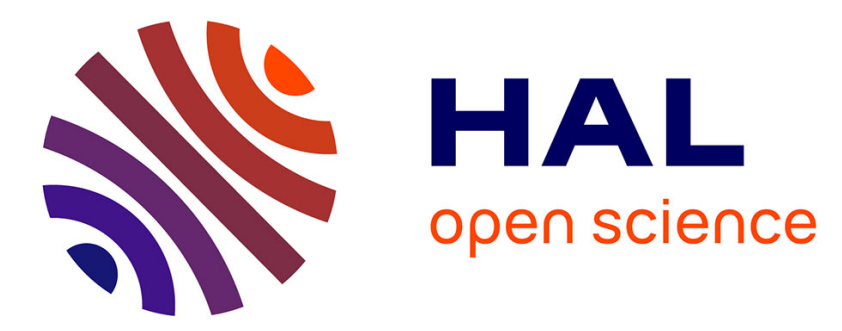

\title{
Microstructural Characterization of Graphite Spheroids in Ductile Iron
}

Koenraad Theuwissen, Marie-Christine Lafont, Lydia Laffont, Bernard Viguier, Jacques Lacaze

\section{- To cite this version:}

Koenraad Theuwissen, Marie-Christine Lafont, Lydia Laffont, Bernard Viguier, Jacques Lacaze. Microstructural Characterization of Graphite Spheroids in Ductile Iron. Transactions of the Indian Institute of Metals, 2012, vol. 65, pp. 627-631. 10.1007/s12666-012-0162-5 . hal-01048727

\section{HAL Id: hal-01048727 \\ https://hal.science/hal-01048727}

Submitted on 25 Jul 2014

HAL is a multi-disciplinary open access archive for the deposit and dissemination of scientific research documents, whether they are published or not. The documents may come from teaching and research institutions in France or abroad, or from public or private research centers.
L'archive ouverte pluridisciplinaire HAL, est destinée au dépôt et à la diffusion de documents scientifiques de niveau recherche, publiés ou non, émanant des établissements d'enseignement et de recherche français ou étrangers, des laboratoires publics ou privés. 


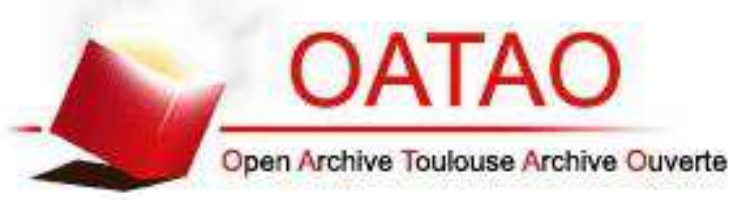

\section{Open Archive Toulouse Archive Ouverte (OATAO)}

OATAO is an open access repository that collects the work of Toulouse researchers and makes it freely available over the web where possible.

This is an author-deposited version published in: http://oatao.univ-toulouse.fr/ Eprints ID: 8714

DOI:10.1007/s12666-012-0162-5

Official URL: http://dx.doi.org/10.1007/s12666-012-0162-5

\section{To cite this version:}

Theuwissen, Koenraad and Lafont, Marie-Christine and Laffont, Lydia and Viguier, Bernard and Lacaze, Jacques Microstructural Characterization of Graphite Spheroids in Ductile Iron. (2012) Transactions of the Indian Institute of Metals, vol. 65 ( ${ }^{\circ}$ 6). pp. 627-631. ISSN 0972-2815

Any correspondence concerning this service should be sent to the repository administrator: staff-oatao@inp-toulouse.fr 


\title{
Microstructural Characterization of Graphite Spheroids in Ductile Iron
}

\author{
Koenraad Theuwissen - Marie-Christine Lafont • \\ Lydia Laffont · Bernard Viguier · Jacques Lacaze
}

\begin{abstract}
The present work brings new insights by transmission electron microscopy allowing disregarding or supporting some of the models proposed for spheroidal growth of graphite in cast irons. Nodules consist of sectors made of graphite plates elongated along a $\langle a\rangle$ direction and stack on each other with their $c$ axis aligned with the radial direction. These plates are the elementary units for spheroidal growth and a calculation supports the idea that new units continuously nucleate at the ledge between sectors.
\end{abstract}

Keywords Solidification - Cast iron - Crystal growth · Graphite $\cdot$ Transmission electron microscopy

\section{Introduction}

60 years ago, the discovery of the spheroidization process of graphite in cast irons was a major breakthrough in materials science and engineering as these alloys then presented a new range of properties and applications. Since then, a significant amount of research has been carried out to determine the growth mechanism of graphite nodules. The present work brings new results allowing disregarding some of the models proposed for this growth while sustaining the bases of others.

Without a spheroidization treatment, growth of graphite in usual cast irons proceeds by rapid extension of the precipitates parallel to the basal plane-i.e. along the $\langle a\rangle$ direction - with frequent bending and branching of the

K. Theuwissen - M.-C. Lafont · L. Laffont · B. Viguier ·

J. Lacaze $(\bowtie)$

CIRIMAT, ENSIACET, Université de Toulouse, BP 44362,

31030 Toulouse, France

e-mail: jacques.lacaze@ensiacet.fr elongated lamellae thus formed. It has been suggested that this growth direction is favoured because of the much higher binding energy between carbon atoms in the basal planes than between graphene layers. On the contrary, graphite spheroids (see Fig. 1) consist of adjacent conical sectors developing radially from the nodule centre, with the graphite $c$ direction parallel to the radius.

It would thus appear that in the case of spheroidal graphite, growth occurs preferentially in the $c$ direction. For some authors, this implied the existence of a mechanism enhancing $c$ axis growth in graphite spheroids at the expense of growth in the $\langle a\rangle$ direction. The presence of screw dislocation spirals in very slowly grown natural graphite $[1,2]$ led Hillert and Lindblom [3] to suggest a model for spheroidal graphite growth based on screw dislocations. In this model, the growth of the cones occurs by addition of atoms at the step ledge of a screw dislocation whose axis is perpendicular to the graphite basal planes. The authors suggested that the elements added for spheroidization $(\mathrm{Mg}, \mathrm{Ce} . .$.$) promote screw dislocations$ by adsorbing onto the graphite lattice. From the observation of graphite grown from the gas phase, Double and Hellawell [4] suggested a very similar model based on cone-helix structures made of curved basal planes. In these structures, the basal planes present rotations around the $c$ axis of graphite at angles corresponding to optimum coincidence configurations between successive graphite layers. Miao et al. [5, 6] have adopted a nearly identical model when their observations by transmission electron microscopy (TEM) showed that the sectors contain numerous crystal defects and particularly tilts around the $c$ axis which can not be reconciled with the nearly perfect alignment of the $c$ axis expected after spiral growth.

In opposition to the above models and following earlier proposals, Sadocha and Gruzleski [7] suggested that growth of graphite spheroids is circumferential rather than 


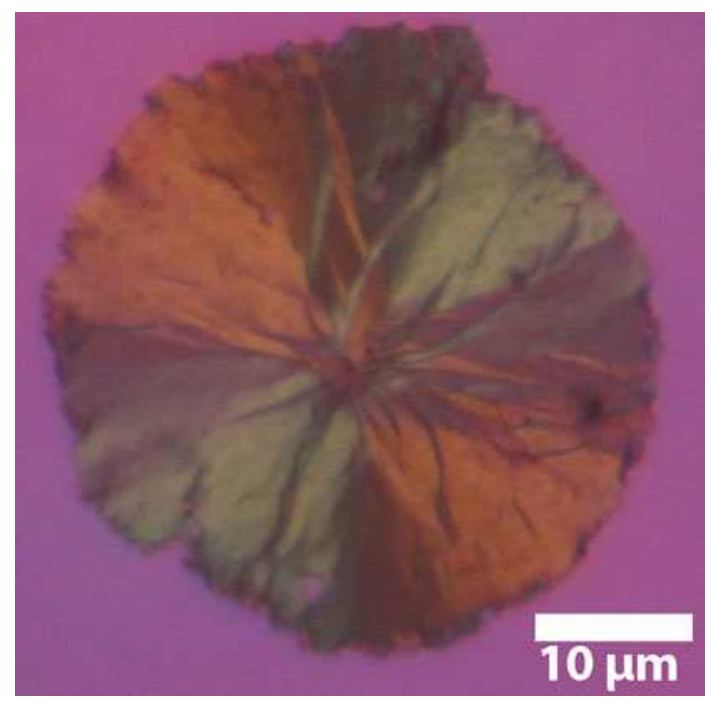

Fig. 1 Optical micrograph (polarized light) of a graphite spheroid in cast iron showing sectors

radial. They proposed that multiple twinning can produce curved crystals, i.e. that spheroidal growth could proceed continuously from spheroidal nuclei. It has indeed been observed repeatedly (e.g. by Liu et al. [8]) that the outer surface of nodules extracted by deep etching sometimes presents extended foliated graphite deposits that give the nodules a cabbage-like shape with leaves partly superposing on each other. However, such a structure where continuously bending graphite foils extend on a significant part of the nodule surface is not representative of the bulk structure and may better be associated to crystallization of amorphous vapour graphite deposits [9] or to solid-state graphite growth in cast iron [10] or steel [11]. In these latter cases, no subgrain boundaries could be observed in clear conflict with the TEM observations mentioned above $[5,6]$.

Multiple twinning to explain spheroidal graphite growth has in fact been proposed for long time by Shubnikov (referenced by Minkoff [12]). Double and Hellawell [13, 14] considered it as a possible mechanism to generate an imperfect sphere with ill fitting junctions offering numerous sources for layer growth. Detailed studies of multiple branching have been performed by Faivre and coworkers $[15,16]$ in the case of pure hexagonal selenium, and Faivre [17] discussed the parallel with spheroidal graphite growth. In the model proposed by these latter authors, a few plates elongate radially from the centre along their $\langle a\rangle$ direction and branch laterally to fill the space between them. Multiple branching then leads to a structure in which a large proportion of the plates have their $c$ direction parallel to the radius of the precipitate. Such a model seems suitable for explaining the initial formation of spheroidal precipitates but could not be extended to late growth of spheroidal graphite as no part of the bulk of spheroids has been reported with the $\langle a\rangle$ direction parallel to the radius.

The present study is one of the very few papers reporting TEM results to characterize spheroidal graphite in cast irons. It was intended to give clue for selecting a model appropriate for describing spheroidal growth, or at least for excluding those unable to do that. Attempt was thus made to characterize the graphite structure along the radial direction of the nodules.

\section{Experimental Details}

The spheroidal graphite cast iron investigated is a standard ferritic alloy used in previous work [18], containing mainly $3.64 \mathrm{wt} \% \mathrm{C}$ and $2.05 \mathrm{wt} \% \mathrm{Si}$. It was spheroidized with a FeSiMg commercial master alloy. The graphite precipitates were of high nodularity, their surface density was evaluated at $400 \mathrm{~mm}^{-2}$ and their mean diameter at $19 \mu \mathrm{m}$. Sections of the iron of $1 \mathrm{~cm}^{2}$ were mechanically ground and polished until $80-100 \mu \mathrm{m}$, then sections of $3 \mathrm{~mm}$ in diameter were stamped, dimpled and thinned by ion-milling to transparency with a low-angle $\left(0-10^{\circ}\right)$ precision ion-beam polishing system (PIPS) to be observed by TEM. Imaging was performed using a JEOL JEM 2010 electron microscope at the Temscan service of the Paul Sabatier University in Toulouse. The TEM apparatus was operated at $200 \mathrm{kV}$ and the diffraction patterns were carried out by selected area diffraction.

It was difficult to find spheroids with appropriate thickness, most of them being electron transparent only at their periphery, or consumed during sample preparation. Further, it is worth stressing that after extensive TEM examination of a given area, amorphisation of the graphite could be noticed. Whilst this radiation damage is known for other carbon materials [19], it has seldom been mentioned in TEM studies of graphite in cast irons. Care was thus taken for minimizing the time during which the beam was focused on the observed areas, particularly when electronic diffraction had to be carried out.

\section{Results}

The photomontage in Fig. 2 shows a graphite nodule whose radius is about $10 \mu \mathrm{m}$. Within this nodule, dark areas are metallic particles containing $\mathrm{Fe}$ and $\mathrm{Si}$ as often observed [20]. The boundary between two sectors can be seen by the change in orientation of the contrast lines, e.g. at the lower right of the photomontage. At the outer limit of the nodules, the sectors appear to be 2-3 $\mu \mathrm{m}$ wide. At a higher magnification, such as in the insert at the upper right of Fig. 2, it is seen that the boundary between adjacent 

photomontage of a graphite nodule. In the insert, bright field image of the boundary between two adjacent sectors and selected area diffraction pattern corresponding to the white open circle in the latter. The angle between the [0001] direction of graphite in the two sectors is $\alpha=31^{\circ}$
Fig. 2 Bright field TEM
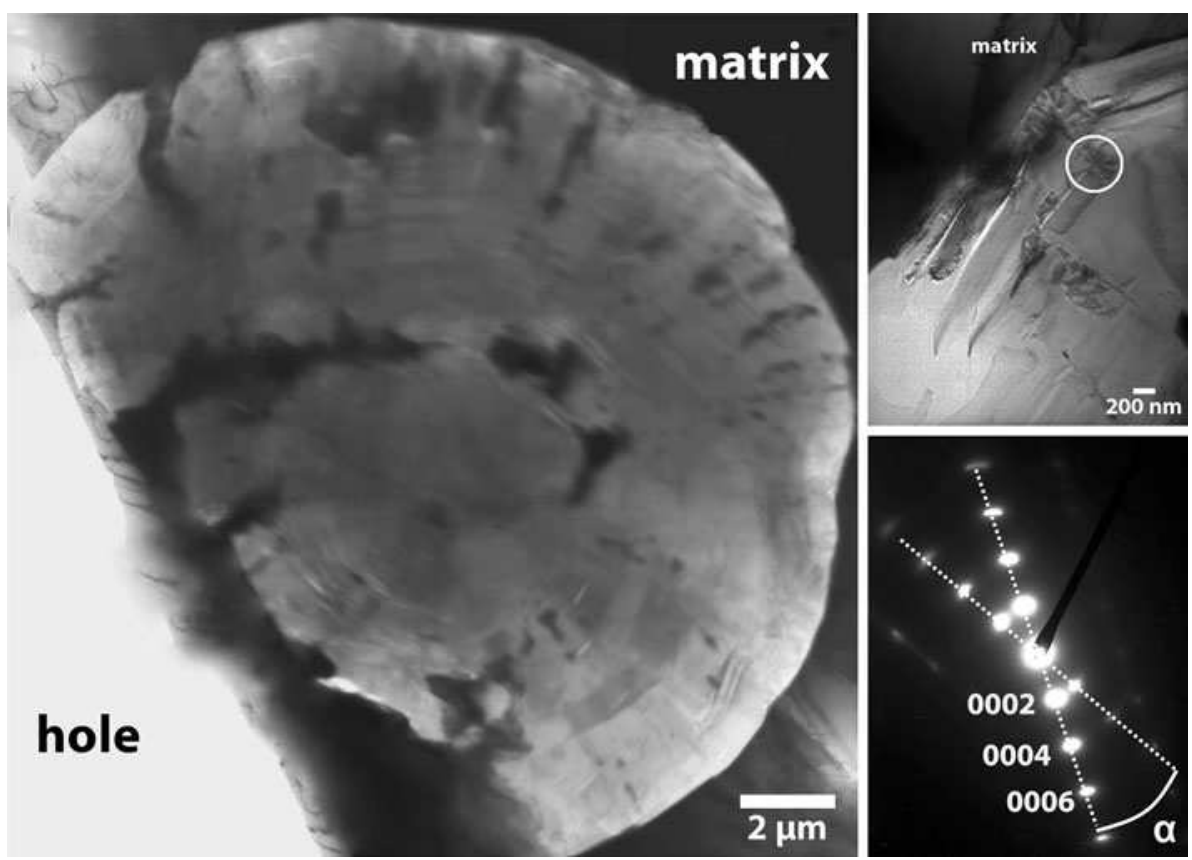

Fig. 3 Bright field image of graphite stacking along a sector of a spheroid and selected area diffraction patterns associated to the numbered areas in the image. The misorientation angles $\alpha$ and $\beta$ amount to $10^{\circ}$ and $11^{\circ}$ respectively
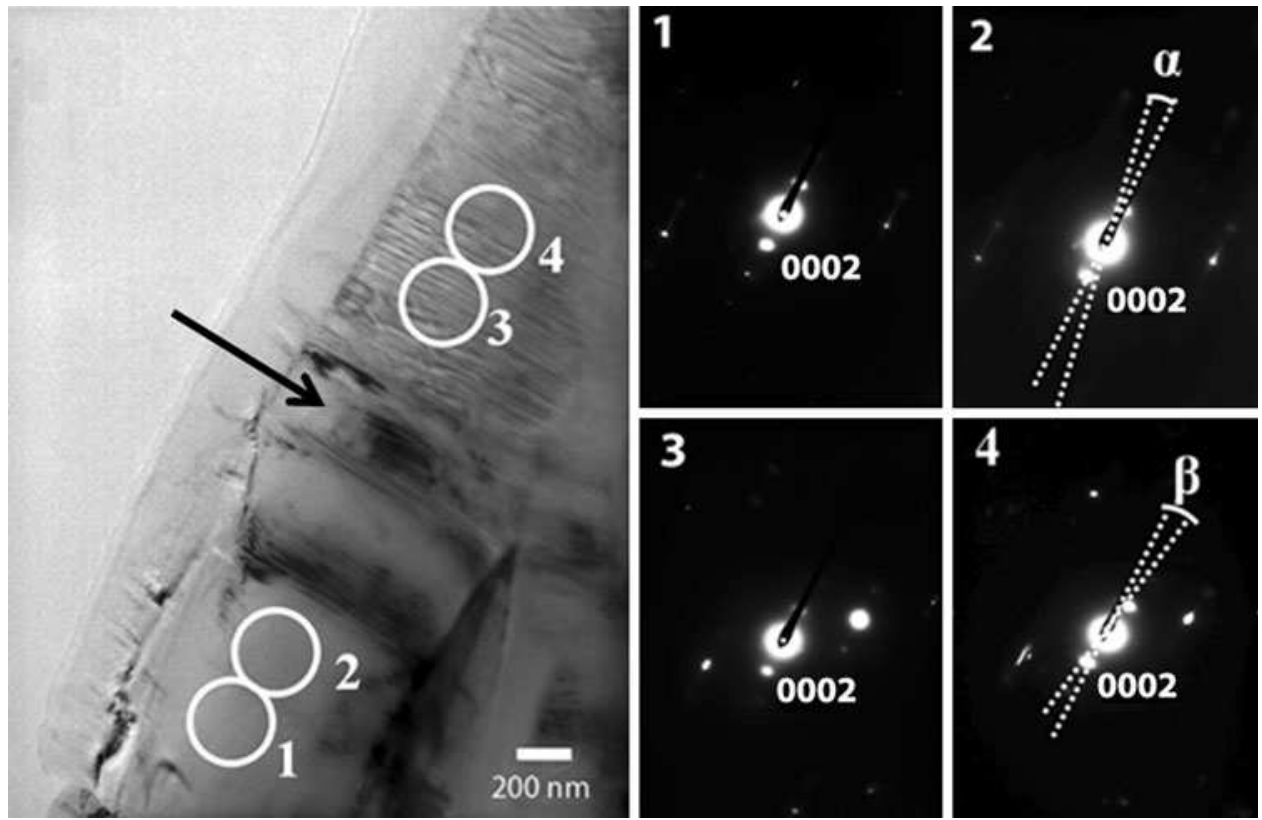

sectors is delineated by the change in the general orientation of the graphite plates stacked on one another in each of the sectors. A few measurements of the angle between the [0001] directions of adjacent sectors were performed as illustrated with the selected area diffraction pattern shown in Fig. 2. Values of $10-15^{\circ}, 20^{\circ}-22^{\circ}$ and $29^{\circ}-30^{\circ}$ have been observed. These high misorientation angles most probably correspond to twins [21] and even higher values at $39^{\circ}-53^{\circ}$ are possible and have been reported [5].

As illustrated in the insert image in Fig. 2, it was generally easy to evidence the stacking of elementary graphite plates at the junction of two sectors. Following research on graphene [22], it is suggested to call these individual plates structural base units (SBU). In the present observations, it was found they have a thickness between 10 and $100 \mathrm{~nm}$, values which are similar to those reported by Miao et al. [5] at $120 \mathrm{~nm}$ and Monchoux et al. [20] at 100-1,000 nm for spheroidal graphite, but also by Double and Hellawell [13] at $100 \mathrm{~nm}$ for lamellar graphite.

In some instances, it was observed that graphite presented microcrystalline areas at the extreme outer periphery of the nodules, over a thickness of about $1 \mu \mathrm{m}$. Such an 
observation has already been reported by Monchoux et al. [20] who related it to solid state precipitation of graphite upon the nodules formed during solidification. As in the case of the extended leaves mentioned above, this feature appears to be peculiar and focus was put later on bulk graphite.

It was thus intended to map the crystallographic orientation of graphite along nodule radii within selected sectors. Figure 3 illustrates one example where this could be achieved over a length of 2 microns. Some areas showed misorientations between each other which could be determined by measuring the angle between their respective (0002) spots in the diffraction patterns (Fig. 3). These misorientations are quite high at $10-11^{\circ}$ but still agree with values reported by Miao et al. [5] and Monchoux et al. [20]. Observations on other sectors showed misorientations ranging from $6^{\circ}$ to $12^{\circ}$, with a peak at $10^{\circ}$. However, in quite many locations, no misorientation could be observed such as the area between diffraction patterns 2 and 3 in Fig. 3. In such locations, fringes which are due to multiple reflections associated with the local high crystalline quality of the graphite could be seen in the bright field image (arrow). While the observation of areas without misorientation would be in favour of the helix-like models, the presence of faults within the same sectors leads to definitely disregard them.

The centre of the spheroids was often too thick for TEM observations. However, a partially torn spheroid shown in

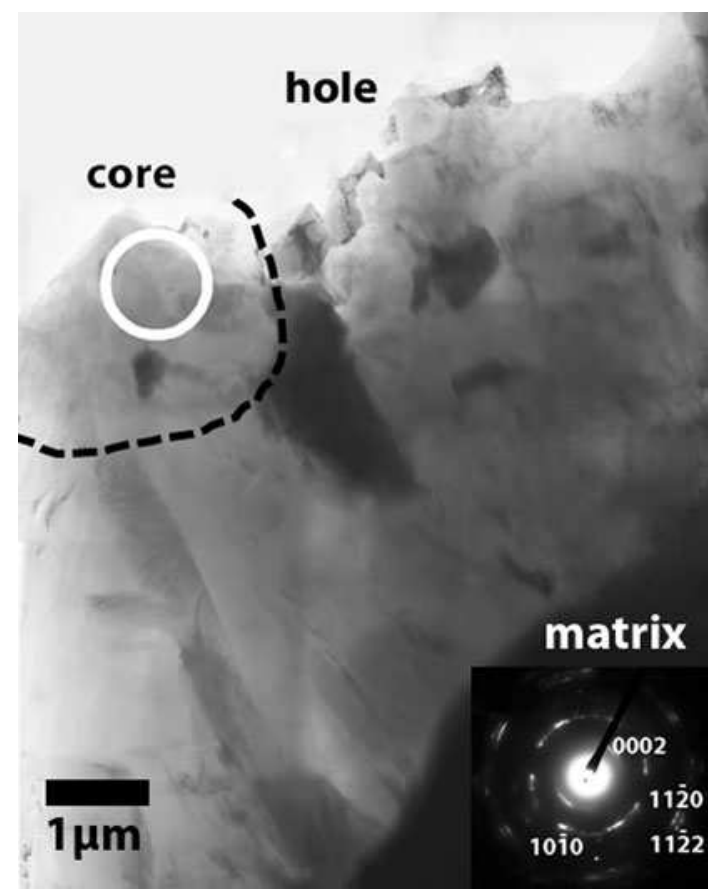

Fig. 4 Bright field image of a graphite spheroid torn by ion milling and diffraction pattern taken at its centre. The selected area aperture diameter is $1 \mu \mathrm{m}$ (white open circle in the bright field image)
Fig. 4 enabled some investigation of the core. The upper part of the figure shows the irregular edges of the hole made by ion milling while the lower right corner (dark contrast) corresponds to the matrix. Several selected area diffraction patterns recorded near the core with a $250 \mathrm{~nm}$ diameter aperture revealed a structure made of small areas with different orientations. The diffraction pattern shown in the figure was taken in this same zone with a $1 \mu \mathrm{m}$ diameter aperture to illustrate the resulting microcrystalline structure at the centre of the spheroid.

\section{Discussion}

It can be considered that graphite in spheroidal graphite cast irons is made of SBU which consist of graphene layers of nanometric size piled up without any crystallographic defect [22]. In the centre of the nodules, the arrangement of these SBU gives a diffraction pattern that appears polycrystalline and could well be in agreement with the multiple branching model described for growth of spheroids in selenium [15-17]. After the core has formed, further growth of the graphite spheroids proceeds with the development of sectors where the SBU stack on each other with the graphite $c$ axis roughly parallel to the radius of nodule. Within the sectors, the SBU can be perfectly stacked over a certain length but will eventually present faults and tilt misorientations between each other. As already stressed, the presence of these faults leads to disregard the models based on a helix which assumes perfect stacking of graphite layers.

The SBU appear to be elongated along their $\langle a\rangle$ direction, exactly as lamellae in cast irons which have not been treated for spheroidization. This means that the growth rate of graphite remains much more rapid along the $\langle a\rangle$ direction than along the $c$ direction, even during spheroidal growth. One way to connect this observation with the overall growth along the $c$ direction is to assume that new SBU are regularly nucleated at the precipitation front. Following Double and Hellawell [13, 14, 23], the most probable locations for the nucleation events are the ledges formed along the outer junctions of neighbouring sectors. It may be imagined that caps of graphite nucleate along these boundaries in epitaxy with one of the sectors over which they expand. It may be postulated that these caps are cylinders elongated along the ledge with a section that is onefourth of a circle whose radius is the critical radius for nucleation, $r_{\mathrm{c}}$. This radius is given by $r_{\mathrm{c}}=\gamma / \Delta \mathrm{G}$, where $\gamma$ is the surface energy and $\Delta \mathrm{G}$ is the driving force that may be estimated as $\Delta \mathrm{G}=\mathrm{L}_{\mathrm{V}}\left(1-\mathrm{T} / \mathrm{T}_{\text {eut }}\right)$, where $\mathrm{L}_{\mathrm{V}}$ is the latent heat of melting per unit volume and $\mathrm{T}_{\text {eut }}$ the eutectic temperature. Using the values selected by Johnson and Smartt [24] for $\gamma$ and $\mathrm{L}_{\mathrm{V}}$ and denoting $\Delta \mathrm{T}=\left(\mathrm{T}_{\text {eut }}-\mathrm{T}\right)$, one gets $r_{\mathrm{c}}(\mathrm{nm})=600 / \Delta \mathrm{T}$. For a typical undercooling $\Delta \mathrm{T}$ 
of $5 \mathrm{~K}$ during eutectic solidification, the critical radius is $60 \mathrm{~nm}$, well within the range experimentally observed for the thickness of the SBU. This simple estimate thus gives support to the model suggested by Double and Hellawell $[13,14,23]$ for spheroidal growth after the sectors have formed.

\section{Conclusion}

The present results lead to disregard any cone-helix model to explain spheroidal growth of graphite in cast irons. Instead, the above views put emphasis on the role of twinning on the formation of the inner part of the nodules as well as on the development of the sectors. However, twinning events should be much more numerous during spheroidal growth than during lamellar growth. It thus seems that the role of $\mathrm{O}$ and $\mathrm{S}$ which are withdrawn from the melt by the spheroidization treatment is not only to create an avalanche of carbon atoms on the prismatic planes (so as to explain the lamellar growth) but also to limit twinning. In this line of thoughts, the effect of some elements on the primary growth of graphite has been recently investigated with secondary ion mass spectroscopy [18] and further TEM investigations are presently being carried out.

\section{References}

1. Horn F H, Nature 170(1952) 581.

2. Roscoe C, Nagle D, and Austerman S B, J Mater Sci 6 (1971) 998.

3. Hillert M, and Lindblom Y, J Iron Steel Inst 148(1954) 388.
4. Double D D, and Hellawell A, Acta Metall 22(1974) 481.

5. Miao B, Fang K, Bian W, and Liu G, Acta Metall Mater 38(1990) 2167.

6. Miao B, Northwood DO, Bian W, Fang K, and Fan M H, J Mater Sci 29(1994) 255.

7. Sadocha J P, and Gruzleski J E, in The Metallurgy of Cast Iron, (eds) Lux B, Minkoff I, and Mollard F, Georgi Pub. Co., St Saphorin (1975) p 443.

8. Liu P C, Loper C R, Kimura T, and Pan E N, AFS Trans 89(1981) 65.

9. Ugarte D, Nature 359(1992) 707.

10. Purdy G R, and Audier M, in The Physical Metallurgy of Cast Irons. MRS symposia proceedings Vol. 34, (eds) Fredriksson H, and Hillert M, North-Holland, Elsevier Science Publishing Co. Inc., Amsterdam (1985), p 13.

11. He K, Daniels H R, Brown A, Brydson R, Edmonds D V, Acta Mater 55(2007) 2919.

12. Minkoff I, The Solidification of metals, The Iron and Steel Institute, London (1967) p 251.

13. Double D D, and Hellawell A, Acta Metall 17(1969) 1071.

14. Double D D, and Hellawell A, in The Metallurgy of Cast Iron, (eds) Lux B, Minkoff I, and Mollard F, Georgi Pub. Co., St Saphorin (1975) p 509.

15. Ryschenkow G, and Faivre G, J Cryst Growth 87(1988) 221.

16. Bisault J, Ryschenkow G, and Faivre G, J Cryst Growth 110(1991) 889.

17. Faivre G, in Physical Metallurgy of Cast Iron V. Advanced materials research Vol. 4-5, (eds) Lesoult G, and Lacaze J, Scitec Publications, Zurich (1997), p 17.

18. Valle N, Theuwissen K, Sertucha J, and Lacaze J, IOP Conf. Series: Mater Sci Eng (2011), 27012026.

19. Banhart F, Rep Prog Phys 62(1999) 1181.

20. Monchoux J P, Verdu C, Thollet G, Fougères R, and Reynaud A, Acta Mater 49(2001) 4355.

21. Bollmann W, and Lux B, in The Metallurgy of Cast Iron, (eds) Lux B, Minkoff I, and Mollard F, Georgi Pub. Co., St Saphorin (1975) p 461.

22. Oberlin A, and Terrière G, J Microsc 18(1973) 247.

23. Double D D, and Hellawell, Acta Mater 43(1995) 2435.

24. Johnson W C, and Smartt H B, Metall Trans A 8A(1977) 553. 